\title{
Indice del volume
}

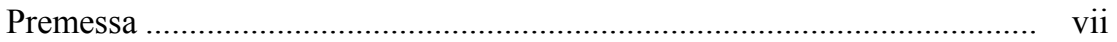

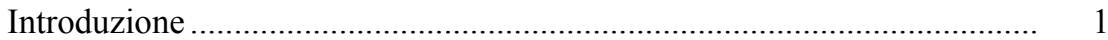

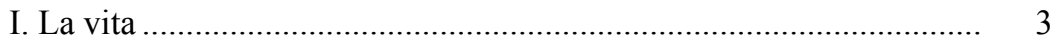

I.1. Lucillio e Nerone.................................................................... 3

I.2. La grafia del nome, lo status, la professione ........................... 5

II. Lucillio e l'epigramma scoptico ........................................................ 9

II.1. La tradizione scommatica di età ellenistica e tardo-ellenistica ................................................................ 9

II.2. L'epigramma scoptico di Lucillio: continuità e

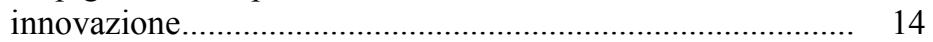

II.3. I monodistici lucilliani: uno schema comico? ........................... 21

II.4. Libro e simposio ................................................................ 25

II.5. Bersagli polemici e nomina ficta ......................................... 27

II.6. Iperbole, gioco con l'assurdo e comicità surreale .................... 31

II.7. Lingua e stile........................................................................ 34

II.8. Lunghezza degli epigrammi e ordine delle parole ................. 38

III. Tecnica della versificazione ......................................................... 40

III.1. Realizzazioni di verso nell'esametro ................................... 40

III.2. Incisioni e leggi metriche....................................................... 42

III.3. Prosodia ........................................................................... 50

III.4. Conclusioni ..................................................................... 54

IV. La tradizione manoscritta .......................................................... 56

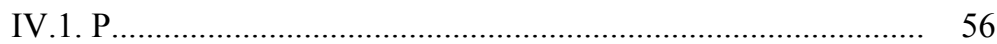

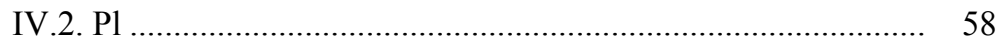

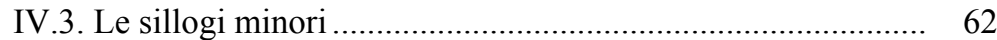

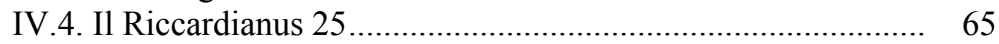

IV.5. Citazioni e testimonianze ……………………..................... 66

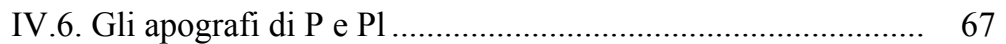

IV.7. Lucillio e l'XI libro dell'Anthologia Palatina ....................... 68

IV.8. I libelli di Lucillio............................................................. 76

IV.9. Il problema delle attribuzioni: Lucillio e Luciano ................. 80

V. La fortuna di Lucillio................................................................ 83

V.1. Lucillio nell'epigramma scoptico greco ………….................. 83

V.2. Lucillio nell'epigramma latino ............................................. 88

V.3. Sopravvivenze di Lucillio a Bisanzio? .................................. 90 
Testo e commento ...................................................................... 95

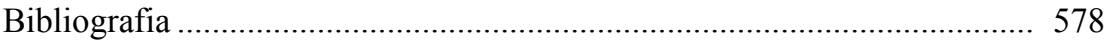

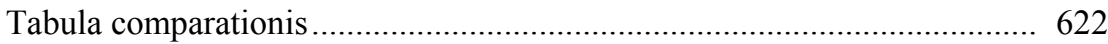

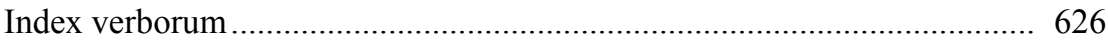

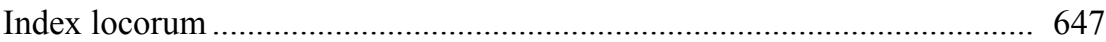

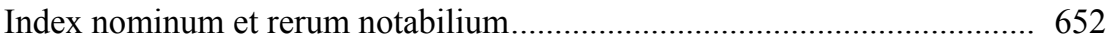

